\title{
A nuclear grading system is a strong predictor of survival in epitheloid diffuse malignant pleural mesothelioma
}

\author{
Kyuichi Kadota ${ }^{1,2}$, Kei Suzuki ${ }^{1}$, Christos Colovos ${ }^{1}$, Camelia S Sima ${ }^{3}$, Valerie W Rusch ${ }^{1}$, \\ William D Travis ${ }^{4}$ and Prasad S Adusumilli ${ }^{1,5}$ \\ ${ }^{1}$ Division of Thoracic Service, Department of Surgery, Memorial Sloan-Kettering Cancer Center, New York, \\ NY, USA; ${ }^{2}$ Department of Diagnostic Pathology, Faculty of Medicine, Kagawa University, Kagawa, Japan; \\ ${ }^{3}$ Department of Epidemiology and Biostatistics, Memorial Sloan-Kettering Cancer Center, New York, NY, \\ USA; ${ }^{4}$ Department of Pathology, Memorial Sloan-Kettering Cancer Center, New York, NY, USA and \\ ${ }^{5}$ Center for Cell Engineering, Memorial Sloan-Kettering Cancer Center, New York, NY, USA
}

Epithelioid mesothelioma is the most prevalent subtype of diffuse malignant pleural mesothelioma in which only staging is prognostic for survival. In this study of epithelioid diffuse malignant pleural mesothelioma, we investigate the prognostic utility of nuclear features. The slides of 232 epithelioid diffuse malignant pleural mesothelioma patients (14 stage I, 54 stage II, 130 stage III, and 34 stage IV) from a single institution were reviewed for the following seven nuclear features: nuclear atypia, nuclear/cytoplasmic ratio, chromatin pattern, intranuclear inclusions, prominence of nucleoli, mitotic count, and atypical mitoses. MIB-1 immunohistochemistry was performed using tissue microarray, and MIB-1 labeling index was recorded as the percentage of positive tumor cells. Median overall survival of all patients was 16 months and correlated with nuclear atypia $(P<0.001)$, chromatin pattern $(P=0.031)$, prominence of nucleoli $(P<0.001)$, mitotic count $(P<0.001)$, and atypical mitoses $(P<0.001)$ by univariate analysis. Multivariate analysis revealed nuclear atypia $(P=0.012)$ and mitotic count $(P<0.001)$ as independent prognostic factors, and these two factors were utilized to create a three-tier nuclear grade score. The resulting nuclear grade stratified patients into three distinct prognostic groups: grade I ( $n=107$, median overall survival $=28$ months), grade II $(n=91,14$ months), and grade III $(n=34$, 5 months). Not only was nuclear grade an independent predictor of overall survival $(\boldsymbol{P}<\mathbf{0 . 0 0 1})$, but it was also a stronger discriminator of survival than all currently available factors. Furthermore, nuclear grade was associated with time to recurrence $(P=0.004)$ in patients who underwent complete surgical resection $(n=159)$. MIB-1 labeling index correlated with mitotic count $(P<0.001)$ and nuclear atypia $(P=0.037)$ and stratified overall survival $(P<0.001)$ and time to recurrence $(P=0.048)$, confirming the prognostic value of the nuclear grade. Nuclear grading in epithelioid mesothelioma provides a simple, practical, and cost-effective prognostic tool that better stratifies clinical outcome and time to recurrence than currently available clinicopathologic factors. Modern Pathology (2012) 25, 260-271; doi:10.1038/modpathol.2011.146; published online 7 October 2011

Keywords: epithelioid mesothelioma; MIB-1; mitosis; nuclear atypia; nuclear grade; survival

Diffuse malignant pleural mesothelioma is an aggressive malignancy of the pleural cavity known to develop after asbestos exposure. ${ }^{1}$ Due to prolonged latency period following asbestos exposure,

Correspondence: Dr PS Adusumilli, MD, Division of Thoracic Service, Department of Surgery, Memorial Sloan-Kettering Cancer Center, New York, NY 10065, USA.

E-mail: adusumip@mskcc.org

Received 9 May 2011; revised 11 August 2011; accepted 22 August 2011; published online 7 October 2011 the incidence is projected to increase in many industrialized countries until 2020. ${ }^{2}$ Despite aggressive trimodality therapy, the prognosis of diffuse malignant pleural mesothelioma remains poor with a median survival of 9-12 months..$^{3-5}$ Challenges in managing diffuse malignant pleural mesothelioma stem from a paucity of prognostic factors in stratifying patients for therapy and clinical outcomes. ${ }^{3,4}$ At this time, therapeutic decisions are based on histology and the TNM staging system. The prognostic utility of the TNM staging is limited to 
differentiating between early stage (I-II) from late stage patients (III-IV) and lacks precision. ${ }^{5}$ Improved prognostic stratification is necessary to optimize treatment options as well as to better stratify patients in clinical trials.

Epithelioid histology is a strong prognostic factor in diffuse malignant pleural mesothelioma and confers a better prognosis compared with biphasic and sarcomatoid histology. ${ }^{4-9}$ Beyond histology, nuclear grading system has been shown to have prognostic utility in breast, ${ }^{10,11}$ renal cell, ${ }^{12,13}$ and bladder carcinomas. ${ }^{14,15}$ Moreover, studies in breast and bladder carcinomas have shown associations between nuclear grading and molecular features, ${ }^{16,17}$ underscoring the importance of nuclear grading beyond prognostic stratification. Yet, no attempts have been made to stratify prognosis by nuclear features within epithelioid diffuse malignant pleural mesothelioma. We herein report a comprehensive pathologic review of 232 epithelioid diffuse malignant pleural mesothelioma patients from a single institution with particular attention to nuclear features. Based on the multivariate analysis of a large series of epithelioid diffuse malignant pleural mesothelioma, we propose a simple prognostic nuclear grading system based on nuclear atypia and mitotic count.

\section{Materials and methods}

\section{Patients}

Clinical and pathological information on 232 patients diagnosed with epithelioid diffuse malignant pleural mesothelioma between 1989 and 2009 at Memorial Sloan-Kettering Cancer Center was collected through the Thoracic Surgery mesothelioma database and the Department of Pathology data file. Institutional Review Board approval was obtained for this study. Clinical variables recorded in the prospectively maintained database included age, gender, laterality, TNM stage, and surgical procedure. TNM staging was based on the reported imaging findings, the surgeon's intraoperative findings, and the pathologic evaluation of the resected specimens using the sixth edition of the American Joint Commission on Cancer Staging Manual. ${ }^{18}$ All patients were followed until date of death or last follow-up.

Pathologic diagnosis was based on standard histologic, histochemical, and immunohistochemical criteria. ${ }^{1,19,20}$ As a positive marker of immunohistochemistry for malignant pleural mesothelioma, standard immunohistochemical markers included calretinin, WT-1, cytokeratin 5/6, and D2-40. As negative markers for malignant pleural mesothelioma, we used carcinoembryonic antigen, CD15, B72.3, BerEP4, and thyroid transcription factor-1. In cases before positive mesothelial markers were available, negative markers were used for making the diagnosis of malignant pleural mesothelioma.
In order to confirm original diagnosis, for specimens where tumor blocks were available, we performed immunohistochemistry for calretinin and WT-1. Only one case was negative for both markers; however, this particular patient's clinical and radiological findings were characteristic of diffuse malignant pleural mesothelioma. The pathological diagnosis was correlated with the gross distribution of tumor and the absence of an intrapulmonary mass lesion on radiologic imaging.

\section{Histologic Evaluation}

All available hematoxylin and eosin (H\&E)-stained slides of each epithelioid diffuse malignant pleural mesothelioma patient (median: 9, range: 1-43 slides/case) were reviewed by a pathologist, and problem cases were reviewed by two pathologists. For each case, we evaluated the following nuclear features: (1) nuclear atypia, (2) nuclear/cytoplasmic (N/C) ratio, (3) chromatin pattern, (4) intranuclear inclusion, (5) prominence of nucleoli, (6) mitotic count, and (7) atypical mitoses. The presence of lymphatic and vascular invasion was also noted if at least one tumor cell cluster was visible within an endothelial lined lymphatic vessel or vein, respectively.

Nuclear features were evaluated using high-powerfield $(\mathrm{HPF})$ at $\times 400$ magnification $\left(0.237 \mathrm{~mm}^{2}\right.$ field of view) using an Olympus BX51 microscope (Olympus, Tokyo, Japan) with a standard eyepiece of $22 \mathrm{~mm}$ diameter. Mitoses were evaluated in $50 \mathrm{HPF}$ areas $\left(11.85 \mathrm{~mm}^{2}\right)$, with the highest mitotic activity identified after scanning through all tumor slides ${ }^{21-24}$ and counted as an average of mitotic figures per $10 \mathrm{HPF}^{22}$

For nuclear atypia, area with the highest degree of atypia (nuclear size and irregularity) was assessed and graded as follows: mild atypia-uniform nuclei in size and shape (Figure 1a), moderate atypianuclei in intermediate size between mild and severe, with slight irregularity in shape (Figure 1b), and severe atypia-bizarre, enlarged nuclei of varied sizes, with some nuclei at least twice as large as others (Figure 1C). ${ }^{11,14,23}$ Nuclear atypia was recorded only if it consisted of $>5 \%$ of the entire tumor area. For each specimen, the most predominant N/C ratio and chromatin patterns were evaluated. N/C ratio was graded as by the following three categories: low $-<1 / 3$ nucleus-to-cytoplasm area (Figure 1d), intermediate-1/3-2/3 (Figure 1b), or high $->2 / 3$ (Figure 1e). Chromatin pattern was graded as homogeneous (Figure 1e), fine granular (Figure 1a), or coarse granular (Figure 1c). ${ }^{25,26}$ Prominence of nucleoli was evaluated using as reference nearby red blood cells, which measured approximately $7 \mu \mathrm{m}$, and graded as the following three categories by the measurement of predominant size: indistinct-inconspicuous or very small (Figure 1a), distinct $-<3 \mu \mathrm{m}$ (Figure 1b), 

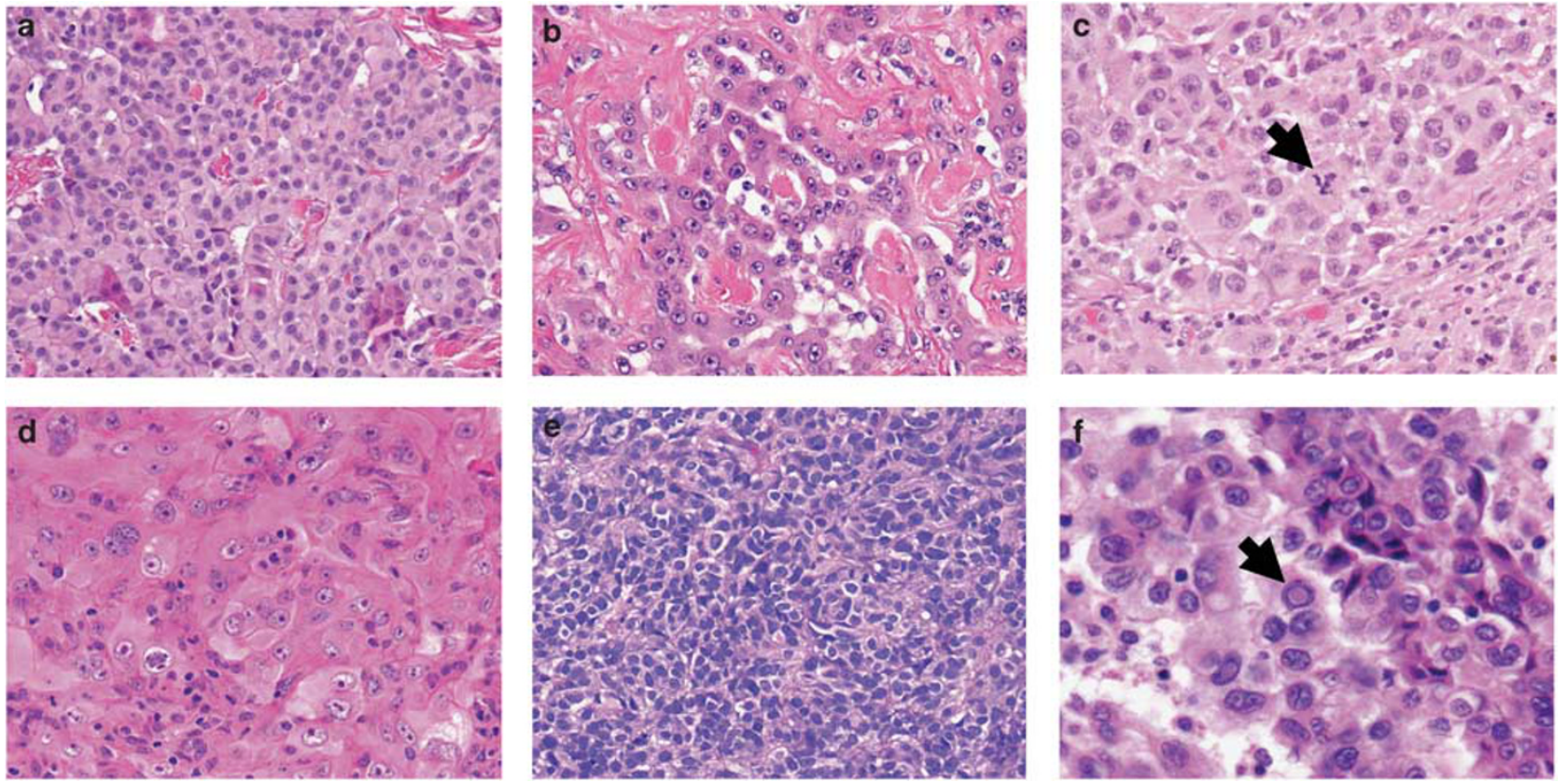

Figure 1 Nuclear features of epithelioid diffuse malignant pleural mesothelioma (H\&E stain; original magnification, $\times 400$ : a-e, $\times 600$ : f). (a) Tumor cells showing mild nuclear atypia, fine granular chromatin, and indistinct nucleoli. (b) Tumor cells showing moderate nuclear atypia, intermediate N/C ratio, and distinct nucleoli. (c) Tumor cells showing severe atypia, coarse granular chromatin, and atypical mitosis (arrow). (d) Tumor cells showing low N/C ratio and large nucleoli. (e) Tumor cells showing high N/C ratio and homogeneous chromatin. (f) Tumor cells with intranuclear inclusion (arrow).

and large $-\geq 3 \mu \mathrm{m}$ (Figure 1d). ${ }^{27}$ Intranuclear inclusions were determined as present or absent by examining 10-50 HPF (Figure 1f), depending on the number of available tumor slides for each case. ${ }^{27}$

We used the following criteria to distinguish mitotic figures from pyknotic cells: absence of a nuclear membrane or a central clear zone, presence of hairy rather than triangular or spiky projections that reflected a mitotic spindle and cytoplasmic basophilia rather than eosinophilia. ${ }^{24}$ Areas of necrosis and prominent stromal fibrosis or inflammation were avoided whenever possible. In the cases in which only small areas of viable tumor were available for review, the best attempt was made to assess the equivalent of 10 full HPF of viable tumor for mitosis counting. ${ }^{22}$ Tumors were graded into the following three groups by mitotic count number using optimal cutoff values associated with the difference in overall survival: low-0-1/10 HPF, intermediate-2-4/10 HPF, and high $-\geq 5 / 10 \mathrm{HPF}$. Atypical mitoses were defined as the presence of abnormal chromosome spread, tripolar or quadripolar forms, circular, or indescribably bizarre forms. ${ }^{28}$ Atypical mitoses were determined as present or absent by examining 10-50 HPF (Figure 1c), depending on the number of available tumor slides for each case.

Additionally, since we recently proposed that pleomorphic epithelioid malignant pleural mesothelioma should be reclassified as biphasic or sarcomatoid mesothelioma due to the poor prognosis, ${ }^{29}$ we further analyzed this data set after excluding the pleomorphic cases.

\section{Tissue Microarray}

Formalin-fixed, paraffin-embedded tumor specimens were used for tissue microarray construction. Briefly, six representative tumor areas were marked on H\&E-stained slides, and cylindrical $0.6-\mathrm{mm}$ tissue cores were arrayed from the corresponding paraffin blocks into a recipient block using an automated tissue arrayer ATA-27 (Beecher Instruments, Sun Prairie, WI, USA), resulting in four tissue microarray blocks. From each tissue microarray, $4-\mu \mathrm{m}$-thick paraffin sections were prepared for immunohistochemistry. In all, 158 cases with adequate cores were available for immunohistochemical analysis.

\section{Immunohistochemistry and Scoring of MIB-1}

Briefly, 4- $\mu \mathrm{m}$ sections from the tissue microarray blocks were deparaffinized in xylene and dehydrated in graded alcohols. Standard avidin-biotin complex peroxidase technique was used for immunohistochemical stain of anti-Ki-67 antibody (clone MIB-1, Immunotech, Westbrook, ME, USA; diluted at $1: 100)$. Sections were stained using a Ventana Discovery XT automated immunohistochemical stainer (Ventana, Tucson, AZ, USA) according to the 
manufacturer's guidelines. Diaminobenzidine was used as the chromogen and hematoxylin as the nuclear counterstain. Positive control tissues were stained in parallel with the study cases.

MIB-1 labeling index was recorded as the percentage of tumor cells with positive nuclear immunostaining in each tissue microarray core. The average values of the cores were considered as MIB-1 labeling index for each patient. For the purpose of survival analysis, tumors were classified into the following two groups by median MIB-1 labeling index $(10.0 \%)$ : low $<10.0 \%$, and high $\geq 10.0 \%$.

\section{Statistical Analysis}

Associations between clinicopathologic variables and histologic findings were analyzed using Fisher's exact test for categorical variables, Cochran Armitage test for ordinal variables, and Wilcoxon test for continuous variables. Overall survival following surgery was estimated using the Kaplan-Meier method, with patients censored if they were alive at the time of last follow-up. An analysis of time to recurrence was restricted to patients who underwent surgery that was deemed to be a complete resection. Non-parametric group comparisons were performed using log-rank test adjusted for stage. ${ }^{30}$ Multivariate analyses were performed using the Cox proportional hazard regression model to study the effects of different variables on overall survival. All $P$-values were based on two-tailed statistical analysis, and a $P$-value $<0.05$ was considered to indicate statistical significance. All analyses were performed using SAS statistical software (version 9.2; SAS Institute, Cary, NC, USA) and the 'clinfun' package in R (http://www.r-project.org).

\section{Results}

\section{Clinicopathologic Demographics and Their Association with Overall Survival}

Clinicopathologic profile of all patients is outlined in Table 1. There were 232 patients with a median age 64 years (range: 29-85), $72 \%$ of which were males. The tumor involved the left pleura in $45 \%$ $(n=104)$ of the cases. Fourteen $(6 \%)$ of the patients were stage I, $54(23 \%)$ were stage II, 130 (56\%) were stage III, and $34(15 \%)$ were stage IV. By procedure, $115(50 \%)$ underwent extrapleural pneumonectomy, $91(39 \%)$ pleurectomy-decortication, and the remaining $26(11 \%)$ had other procedures (11 biopsies, 10 exploratory thoracotomies, 3 palliative pleurectomies, and 2 video-assisted thoracoscopic surgeries). Lymphatic invasion was detected in $44 \%$ $(n=102)$, and vascular invasion in $23 \%(n=54)$.

Among all patients, median overall survival was 16 months, with a 2-year overall survival of $34 \%$ and 5-year overall survival of $11 \%$. On univariate analyses, older age ( $>65$ years $)(P=0.046)$,
Table 1 Univariate analysis in predicting overall survival by clinicopathologic factors

\begin{tabular}{|c|c|c|c|}
\hline Variables & $\begin{array}{l}\text { Patients } \\
(\%)\end{array}$ & $\begin{array}{c}\text { Median } \\
\text { overall } \\
\text { survival } \\
\text { (months) }\end{array}$ & P-value \\
\hline All patients & $232(100)$ & 16 & \\
\hline Age (years) & & & 0.046 \\
\hline$\leq 65$ & $132(57)$ & 18 & \\
\hline$>65$ & $100(43)$ & 15 & \\
\hline Gender & & & 0.065 \\
\hline Female & $64(28)$ & 21 & \\
\hline Male & $168(72)$ & 15 & \\
\hline Laterality & & & 0.040 \\
\hline Left & $104(45)$ & 17 & \\
\hline Right & $128(55)$ & 15 & \\
\hline T stage & & & 0.013 \\
\hline $\mathrm{T} 1$ & $20(9)$ & 24 & (T1-2 vs T3-4) \\
\hline $\mathrm{T} 2$ & $88(38)$ & 18 & \\
\hline T3 & $97(42)$ & 15 & \\
\hline $\mathrm{T} 4$ & $27(12)$ & 14 & \\
\hline$N$ stage & & & 0.092 \\
\hline No & $139(60)$ & 19 & (N0 vs N1-3) \\
\hline N1 & $17(7)$ & 8 & \\
\hline N2 & $74(32)$ & 11 & \\
\hline N3 & $2(1)$ & Not applicable & \\
\hline Stage & & & 0.007 \\
\hline I & $14(6)$ & 22 & (I-II vs III-IV) \\
\hline II & $54(23)$ & 19 & \\
\hline III & $130(56)$ & 14 & \\
\hline IV & 34 (15) & 15 & \\
\hline Surgical procedure & & & 0.472 \\
\hline EPP & $115(50)$ & 13 & \\
\hline $\mathrm{PD}$ & 91 (39) & 19 & \\
\hline Other procedures & $26(11)$ & 15 & \\
\hline Lymphatic invasion & & & $<0.001$ \\
\hline Absent & $130(56)$ & 22 & \\
\hline Present & $102(44)$ & 11 & \\
\hline Vascular invasion & & & $<0.001$ \\
\hline Absent & $178(77)$ & 18 & \\
\hline Present & $54(23)$ & 9 & \\
\hline
\end{tabular}

EPP, extrapleural pneumonectomy; PD, pleurectomy/decortication

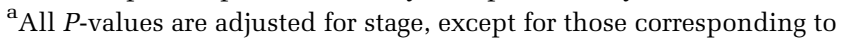
$\mathrm{T}$ stage, $\mathrm{N}$ stage, and stage.

right-sided disease $(P=0.040)$, higher $\mathrm{T}$ stage (T3-4) $(P=0.013)$, advanced stage (stages III-IV) $(P=0.007)$, lymphatic invasion $(P<0.001)$, and vascular invasion $(P<0.001)$ were associated with worse overall survival (Table 1).

\section{Nuclear Features and Their Association with Overall Survival}

Nuclear features and their association with overall survival are outlined in Table 2. Of the seven nuclear features examined, five were significant 
Table 2 Univariate analysis in predicting overall survival by nuclear features

\begin{tabular}{|c|c|c|c|}
\hline Variables & $\begin{array}{l}\text { Patients } \\
(\%)\end{array}$ & $\begin{array}{l}\text { Median } \\
\text { overall } \\
\text { survival } \\
\text { (months) }\end{array}$ & $\mathrm{P}$-value ${ }^{\mathrm{a}}$ \\
\hline All patients & 232 (100) & 16 & \\
\hline $\begin{array}{l}\text { Nuclear atypia } \\
\quad \text { Mild } \\
\text { Moderate } \\
\text { Severe }\end{array}$ & $\begin{array}{r}112(48) \\
74(32) \\
46(20)\end{array}$ & $\begin{array}{r}23 \\
15 \\
8\end{array}$ & $<0.001$ \\
\hline $\begin{array}{l}\text { Nuclear/cytoplasmic ra } \\
\text { Low } \\
\text { Intermediate } \\
\text { High }\end{array}$ & $\begin{array}{l}\text { tio } \\
86(37) \\
104(45) \\
42(18)\end{array}$ & $\begin{array}{l}15 \\
17 \\
19\end{array}$ & 0.572 \\
\hline $\begin{array}{l}\text { Chromatin pattern } \\
\text { Homogeneous } \\
\text { Fine granular } \\
\text { Coarse granular }\end{array}$ & $\begin{array}{r}24(10) \\
112(48) \\
96(41)\end{array}$ & $\begin{array}{l}25 \\
19 \\
11\end{array}$ & 0.031 \\
\hline $\begin{array}{l}\text { Intranuclear inclusion } \\
\text { Absence } \\
\text { Presence }\end{array}$ & $\begin{array}{r}225(97) \\
7(3)\end{array}$ & $\begin{array}{l}16 \\
18\end{array}$ & 0.686 \\
\hline $\begin{array}{l}\text { Prominence of nucleoli } \\
\text { Indistinct } \\
\text { Distinct } \\
\text { Large }\end{array}$ & $\begin{array}{r}55(24) \\
122(53) \\
55(24)\end{array}$ & $\begin{array}{l}25 \\
16 \\
11\end{array}$ & $<0.001$ \\
\hline $\begin{array}{l}\text { Mitotic count } \\
\text { Low } \\
\text { Intermediate } \\
\text { High }\end{array}$ & $\begin{array}{l}75(32) \\
76(33) \\
81(35)\end{array}$ & $\begin{array}{l}31 \\
17 \\
10\end{array}$ & $<0.001$ \\
\hline $\begin{array}{l}\text { Atypical mitosis } \\
\text { Absence } \\
\text { Presence }\end{array}$ & $\begin{array}{r}177(76) \\
55(24)\end{array}$ & $\begin{array}{r}19 \\
8\end{array}$ & $<0.001$ \\
\hline
\end{tabular}

${ }^{\text {a } A l l ~} P$-values are adjusted for stage.

predictors of overall survival: nuclear atypia $(P<0.001)$, chromatin pattern $(P=0.031)$, prominence of nucleoli $(P<0.001)$, mitotic count $(P<0.001)$, and atypical mitoses $(P<0.001)$. Nuclear atypia $(P=0.005)$, mitotic count $(P<0.001)$, and the presence of atypical mitoses $(P<0.001)$ were prognostic of overall survival in the 68 early stage patients (stages I-II). As well, nuclear atypia $(P<0.001)$, prominence of nucleoli $(P=0.002)$, mitotic count $(P<0.001)$, and presence of atypical mitoses $(P<0.001)$ correlated with overall survival in the 130 stage III patients.

For nuclear atypia, patients with severe atypia had the worst median overall survival $(n=46,8$ months), followed by moderate ( $n=74,15$ months) and mild ( $n=112,23$ months) (Figure 2a). Overall survival was significantly different between severe and moderate atypia as well as moderate and mild atypia $(P=0.003$ and $P=0.003$, respectively). For chromatin pattern, patients with coarse granular chromatin had the worst median overall survival ( $n=96,11$ months), followed by fine granular
( $n=112,19$ months) and homogeneous $(n=24,25$ months) (Figure 2b). Patients with large nucleoli had the worst median overall survival $(n=55$, 11 months), followed by distinct $(n=122,16$ months) and indistinct ( $n=55,25$ months) (Figure 2c). Mitotic count ranged from 0 to 64 per $10 \mathrm{HPF}$ (median, 3.0; mean \pm s.d., $5.0 \pm 6.9$ ), and patients with high mitotic counts had the worst median overall survival ( $n=81,10$ months), followed by intermediate $(n=76,17$ months) and low mitotic counts $(n=75,31$ months) (Figure 2d). Overall survival was significantly different between high and intermediate mitotic counts as well as intermediate and low $(P<0.001$ and $P=0.003$, respectively). The presence of atypical mitoses were associated with worse median overall survival ( $n=55,8$ months) compared with absence $(n=177,19$ months $)(P<0.001) . \mathrm{N} / \mathrm{C}$ ratio was not a significant prognostic factor. Intranuclear inclusion was seen only in seven cases, which was not insufficient to perform overall survival analysis.

On multivariate analysis of nuclear features, nuclear atypia (hazard ratio $(\mathrm{HR})=1.89,95 \%$ confidence interval $(\mathrm{CI})=1.15-3.10, \quad P=0.012)$ and mitotic count $(\mathrm{HR}=2.79, \quad 95 \% \quad \mathrm{CI}=1.69-4.59$, $P<0.001)$ were found to be independent prognostic factors (Table 3 ).

\section{Nuclear Grading System in Epithelioid Diffuse Malignant Pleural Mesothelioma}

We developed a nuclear grading system based on the two independent prognostic factors on multivariate analysis-nuclear atypia and mitotic count. For nuclear atypia, tumors were scored as 1 for mild, 2 for moderate, and 3 for severe atypia. For mitotic count, tumors were scored as 1 for low, 2 for intermediate, and 3 for high. In each case, a total score was computed as the sum of the twoparameter scores, ranging from 2 to 6 . Figure 3a shows the overall survival curve in all patients by this scoring scheme. Scores of $2(n=60$, median overall survival $=31$ months $)$ and $3(n=47,24$ months) showed the best overall survival. Scores of $4(n=52,15$ months $)$ and $5(n=39,12$ months $)$ showed similar outcome with intermediate overall survival. A score of 6 showed the worst overall survival ( $n=34,5$ months). On the basis of these results, we simplified our scoring scheme into a three-tier grade: grade I for total scores 2 or 3, grade II for total scores 4 or 5 , and grade III for a total score 6 . Patients with nuclear grade III $(n=34)$ had the worst median overall survival (5 months), followed by grade II ( $n=91,14$ months) and grade I ( $n=107$, 28 months) $(P<0.001)$ (Figure $3 \mathrm{~b})$, with significant differences seen between each grade $(P<0.001$ for grades I vs II, $P=0.001$ for grades II vs III). These observations were replicated in a cohort of 68 early stage patients (stages I-II) $(P<0.001)$ and in 130 stage III patients $(P<0.001)$. 


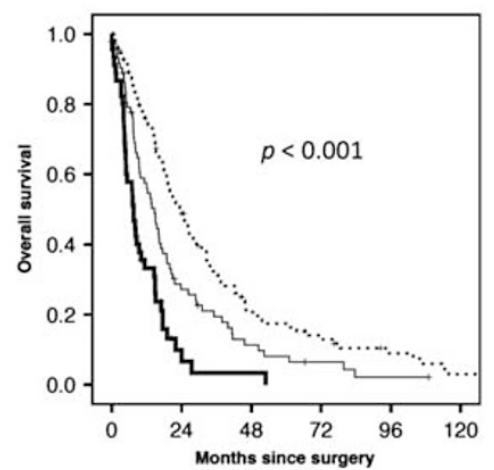

b

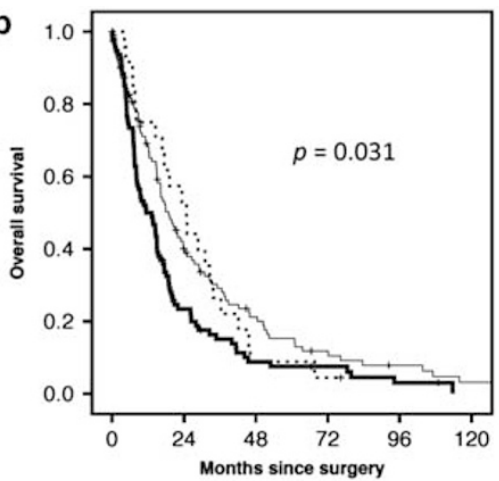

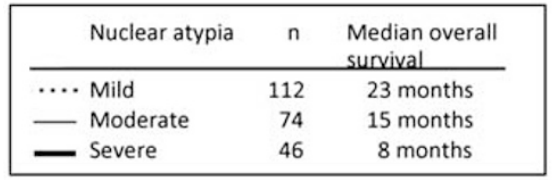

\begin{tabular}{|lrc|}
\hline Chromatin & $\mathrm{n}$ & $\begin{array}{l}\text { Median overall } \\
\text { survival }\end{array}$ \\
\hline$\cdots$ Homogeneous & 24 & 25 months \\
- Fine granular & 112 & 19 months \\
Coarse granular & 96 & 11 months \\
\hline
\end{tabular}

C

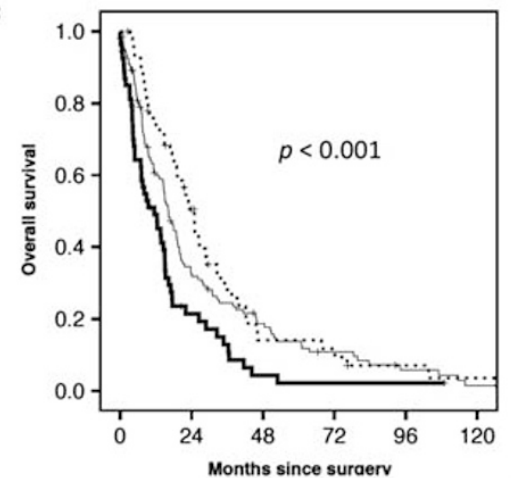

d

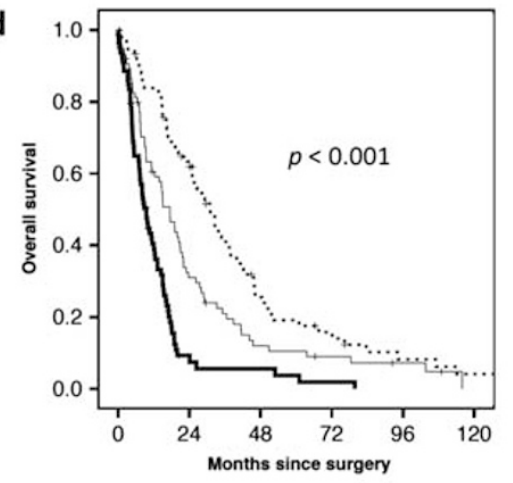

\begin{tabular}{llc|} 
Mitotic count & $\mathrm{n}$ & $\begin{array}{c}\text { Median overall } \\
\text { survival }\end{array}$ \\
\hline$\cdots$ Low & 75 & 31 months \\
- Intermediate & 76 & 17 months \\
High & 81 & 10 months \\
\hline
\end{tabular}

Figure 2 Overall survival by nuclear features in all patients. (a) Patients with severe nuclear atypia had the worst median overall survival, followed by moderate and mild. (b) Patients with coarse granular chromatin had the worst median overall survival, followed by fine granular and homogeneous. (c) Patients with large nucleoli had the worst median overall survival, followed by distinct and indistinct. (d) Patients with high mitotic count had the worst median overall survival, followed by intermediate and low.

On multivariate analysis including all factors found to be prognostic in our series, in addition to right-sided disease $(\mathrm{HR}=1.36,95 \% \mathrm{CI}=1.01-1.83$, $P=0.046)$ and lymphatic invasion $(\mathrm{HR}=1.50$, $95 \% \mathrm{CI}=1.09-2.08, P=0.014$ ), nuclear grade (II $v s$ I: $\mathrm{HR}=2.11,95 \% \mathrm{CI}=1.52-2.94, P<0.001$; III $v s$ II: $\mathrm{HR}=4.16, \quad 95 \% \mathrm{CI}=2.47-7.03, P<0.001)$ was a strong independent predictor of worse overall survival, as shown in Table 4.

As we have recently proposed to reclassify the pleomorphic subtype epithelioid diffuse malignant pleural mesothelioma as biphasic or sarcomatoid due to poor prognosis, ${ }^{29}$ we repeated our analysis of nuclear features in a cohort of epithelioid diffuse malignant pleural mesothelioma excluding the 34 pleomorphic cases. In these 198 patients, our findings of nuclear features remained significant. Patients with severe atypia had the worst median overall survival ( $n=12,5$ months) followed by moderate ( $n=74,15$ months $)$ and mild $(n=112,23$ months) $(P<0.001)$. Patients with high mitotic count had the worst median overall survival $(n=56$, 11 months), followed by intermediate $(n=68,18$ months) and low $(n=74,31$ months $)(P<0.001)$. Nuclear grading remained prognostic with grade III patients exhibiting the worst median overall survival ( $n=9,5$ months), followed by grade II $(n=82,13$ months $)$ and grade I $(n=107,28$ months $)(P<0.001)$.

\section{Association Between Nuclear Grade and Time to Recurrence}

Having shown the value of nuclear features in predicting overall survival, we next sought to determine their prognostic value in predicting 
recurrence. Among 159 patients who underwent complete resection, patients with severe nuclear atypia $(n=31)$ had the shortest median time to recurrence (14 months), followed by moderate atypia $(n=53,18$ months $)$ and mild atypia $(n=75$, 25 months $)(P=0.037$; Figure 4a). Patients with high $(n=57)$ and intermediate mitotic counts $(n=60)$ had shorter median time to recurrence (14 and 16 months, respectively) than low ( $n=42,67$ months) $(P<0.001$; Figure 4b). Patients with nuclear grade II

Table 3 Multivariate analysis in predicting overall survival by nuclear features

\begin{tabular}{lccr}
\hline Variables & $\begin{array}{c}\text { Hazard } \\
\text { ratio }\end{array}$ & $\begin{array}{c}95 \% \\
\text { CI }\end{array}$ & P-value \\
& & & \\
\hline $\begin{array}{l}\text { Nuclear atypia } \\
\quad \text { Moderate vs mild }\end{array}$ & 1.30 & $0.92-1.83$ & 0.138 \\
$\quad$ Severe vs mild & 1.89 & $1.15-3.10$ & 0.012 \\
& & & \\
Chromatin pattern & 1.52 & $0.82-2.81$ & 0.181 \\
$\quad$ Fine granular vs homogeneous & 1.06 & $0.74-1.50$ & 0.754 \\
$\quad$ Coarse granular vs homogeneous & & & \\
& & & \\
Prominence of nucleoli & 0.79 & $0.48-1.31$ & 0.365 \\
$\quad$ Distinct vs indistinct & 0.81 & $0.55-1.19$ & 0.280 \\
$\quad$ Large vs indistinct & & & \\
& & & \\
Mitotic count & 1.55 & $1.05-2.28$ & 0.028 \\
$\quad$ Intermediate vs low & 2.79 & $1.69-4.59$ & $<0.001$ \\
$\quad$ High vs low & & & \\
Atypical mitosis & 1.02 & $0.60-1.72$ & 0.948 \\
$\quad$ Presence vs absence & & & \\
\hline
\end{tabular}

CI, confidence interval.
( $n=69,16$ months) had shorter median time to recurrence than grade I ( $n=68,37$ months), while the median was not met in patients with grade III $(n=22)(P=0.004$; Figure 4c). Similar observations by nuclear atypia, mitotic count, and nuclear grade were made in a cohort of 53 early stage patients (stages I-II) $(P=0.019,0.003$, and 0.012 , respectively) and 99 stage III patients $(P=0.023,0.035$, and 0.017 , respectively).

\section{Association Between Nuclear Features and Clinicopathologic Factors}

Severe nuclear atypia was associated with lymphatic invasion $(P<0.001)$, vascular invasion $(P<0.001)$, and increased T stage $(P=0.037)$. High mitotic count was associated with lymphatic invasion $(P<0.001)$, vascular invasion $(P<0.001)$, lymph node metastasis $(P<0.001)$, and advanced stage (stages III and IV) $(P=0.008)$. Higher nuclear

Table 4 Multivariate analysis in predicting overall survival

\begin{tabular}{lccr}
\hline Variables & $\begin{array}{c}\text { Hazard } \\
\text { ratio }\end{array}$ & $\begin{array}{c}95 \% \\
\text { CI }\end{array}$ & P-value \\
\hline Age (>65 vs $\leq 65$ ) (years) & 1.26 & $0.95-1.67$ & 0.105 \\
Laterality (right vs left) & 1.36 & $1.01-1.83$ & 0.046 \\
Stages (III-IV vs I-II) & 1.39 & $0.99-1.94$ & 0.152 \\
Lymphatic invasion & 1.50 & $1.09-2.08$ & 0.014 \\
Vascular invasion & 0.88 & $0.57-1.37$ & 0.578 \\
Nuclear grade (II vs I) & 2.11 & $1.52-2.94$ & $<0.001$ \\
Nuclear grade (III vs II) & 4.16 & $2.47-7.03$ & $<0.001$
\end{tabular}

CI, confidence interval.

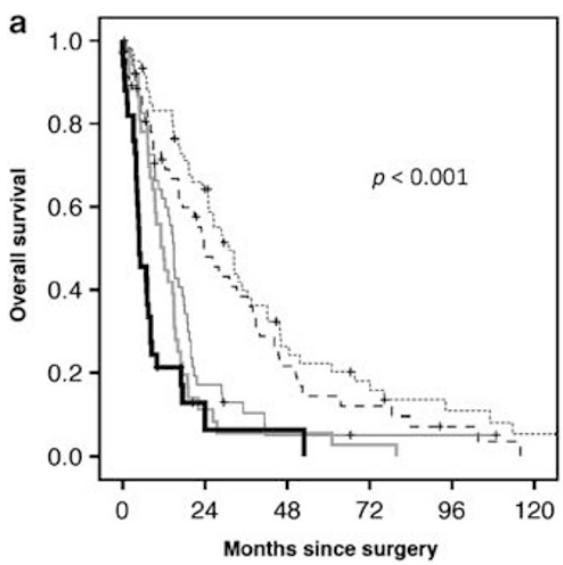

\begin{tabular}{llrr} 
Total score & $\mathrm{n}$ & $\begin{array}{c}\text { Median overall } \\
\text { survival }\end{array}$ \\
\hline$\cdots 2$ & 60 & 31 months \\
--3 & 47 & 24 months \\
-4 & 52 & 15 months \\
-5 & 39 & 12 months \\
-6 & 34 & 5 months
\end{tabular}

b

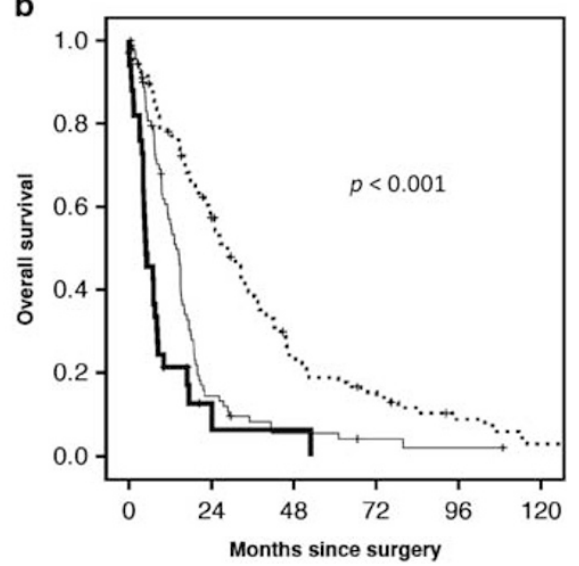

\begin{tabular}{|lrc|}
\hline Nuclear grade & $n$ & $\begin{array}{l}\text { Median overall } \\
\text { survival }\end{array}$ \\
\hline$\cdots$ Grade I & 107 & 28 months \\
- Grade II & 91 & 14 months \\
- Grade III & 34 & 5 months \\
\hline
\end{tabular}

Figure 3 Overall survival by nuclear grade in all patients. (a) Nuclear grading scores of 2 and 3 had the best overall survival. Score of 4 and 5 showed similar overall survival curves, with an intermediate overall survival. Total score of 6 showed the worst overall survival. (b) Patients with grade III had the worst median overall survival, followed by grade II and grade I. 

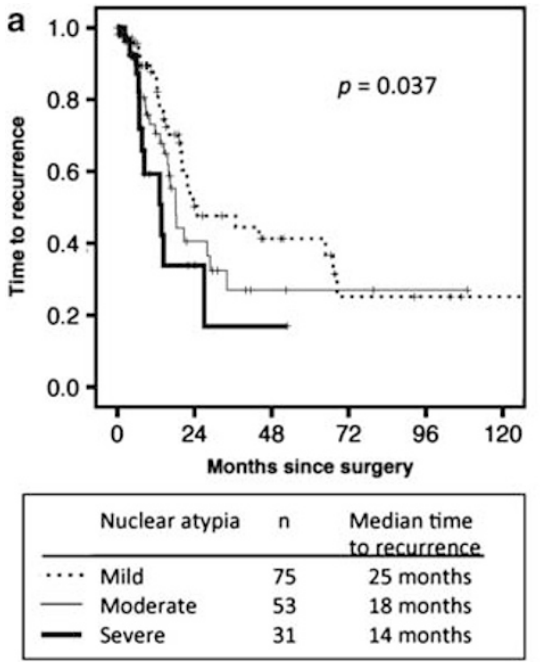
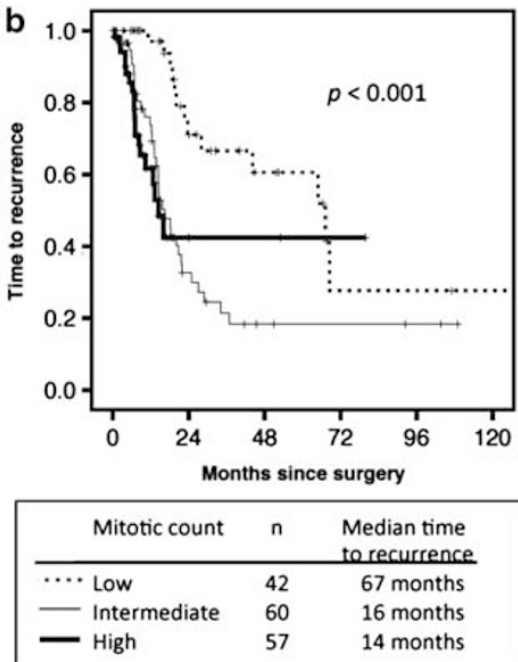

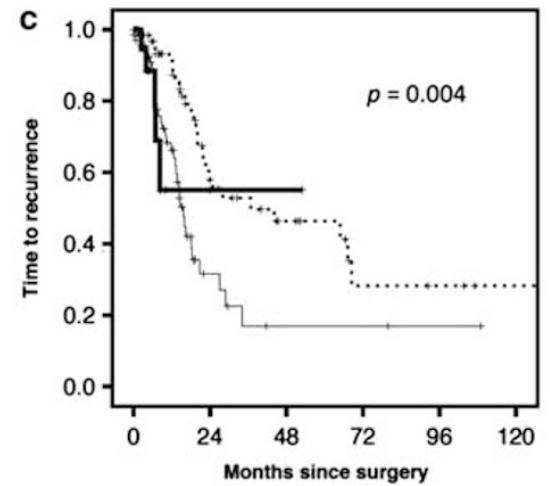

\begin{tabular}{|lcc|}
\hline Nuclear grade & $n$ & $\begin{array}{c}\text { Median time } \\
\text { te recurrence }\end{array}$ \\
\hline$\cdots$ Grade I & 68 & 37 months \\
- Grade II & 69 & 16 months \\
Grade III & 22 & Not met \\
\hline
\end{tabular}

Figure 4 Association of time to recurrence with nuclear grade in all patients. (a) Patients with severe nuclear atypia had the shortest median time to recurrence, followed by moderate and mild atypia. (b) Patients with high and intermediate mitotic count had shorter median time to recurrence than low. (c) Patients with nuclear grade II had shorter median time to recurrence than grade I.

Table 5 Distribution of clinicopathologic factors by nuclear grade

Variables All patients Grade I Grade II Grade III P-value

\begin{tabular}{|c|c|c|c|c|c|}
\hline All patients (\%) & $232(100)$ & $107(46)$ & 91 (39) & $34(15)$ & \\
\hline $\begin{array}{l}\text { Age (years) } \\
\text { Median } \\
\text { Range }\end{array}$ & $\begin{array}{c}64 \\
29-85\end{array}$ & $\begin{array}{c}62 \\
34-85\end{array}$ & $\begin{array}{c}61 \\
29-79\end{array}$ & $\begin{array}{c}61 \\
35-81\end{array}$ & 0.867 \\
\hline $\begin{array}{l}\text { Gender (\%) } \\
\text { Female } \\
\text { Male }\end{array}$ & $\begin{array}{r}64(28) \\
168(72)\end{array}$ & $\begin{array}{l}34(32) \\
73(68)\end{array}$ & $\begin{array}{l}26(29) \\
65(71)\end{array}$ & $\begin{array}{r}4(12) \\
30(88)\end{array}$ & 0.043 \\
\hline $\begin{array}{l}\text { Laterality (\%) } \\
\text { Left } \\
\text { Right }\end{array}$ & $\begin{array}{l}104(45) \\
128(55)\end{array}$ & $\begin{array}{l}49(46) \\
58(54)\end{array}$ & $\begin{array}{l}40(44) \\
51(56)\end{array}$ & $\begin{array}{l}15(44) \\
19(56)\end{array}$ & 0.810 \\
\hline $\begin{array}{l}\text { Lymphatic invasi } \\
\text { Absence } \\
\text { Presence }\end{array}$ & $\begin{array}{l}\text { on }(\%) \\
130(56) \\
102(44)\end{array}$ & $\begin{array}{l}77(72) \\
30(28)\end{array}$ & $\begin{array}{l}43(47) \\
48(53)\end{array}$ & $\begin{array}{l}10(29) \\
24(71)\end{array}$ & $<0.001$ \\
\hline $\begin{array}{l}\text { Vascular invasior } \\
\text { Absence } \\
\text { Presence }\end{array}$ & $\begin{array}{l}(\%) \\
178(77) \\
54(23)\end{array}$ & $\begin{array}{r}100(93) \\
7(7)\end{array}$ & $\begin{array}{l}67(74) \\
24(26)\end{array}$ & $\begin{array}{l}11(32) \\
23(68)\end{array}$ & $<0.001$ \\
\hline $\begin{array}{l}\text { T stage (\%) } \\
\text { T1-2 } \\
\text { T3-4 }\end{array}$ & $\begin{array}{l}108(47) \\
124(53)\end{array}$ & $\begin{array}{l}52(49) \\
55(51)\end{array}$ & $\begin{array}{l}48(53) \\
43(47)\end{array}$ & $\begin{array}{r}8(24) \\
26(76)\end{array}$ & 0.065 \\
\hline $\begin{array}{l}N \text { stage (\%) } \\
\text { No } \\
\text { N1-3 }\end{array}$ & $\begin{array}{r}139(60) \\
93(40)\end{array}$ & $\begin{array}{l}73(68) \\
34(32)\end{array}$ & $\begin{array}{l}47(52) \\
44(48)\end{array}$ & $\begin{array}{l}19(56) \\
15(44)\end{array}$ & 0.054 \\
\hline $\begin{array}{l}\text { Stage (\%) } \\
\text { I-II } \\
\text { III-IV }\end{array}$ & $\begin{array}{r}68(29) \\
164(71)\end{array}$ & $\begin{array}{l}39(36) \\
68(64)\end{array}$ & $\begin{array}{l}26(29) \\
65(71)\end{array}$ & $\begin{array}{c}3(9) \\
31(91)\end{array}$ & 0.003 \\
\hline
\end{tabular}

grade was associated with male gender $(P=0.043)$, lymphatic invasion $(P<0.001)$, vascular invasion $(P<0.001)$, advanced overall stage $(P=0.003)$, and showed an increased tendency for higher $\mathrm{T}$ stage
$(P=0.065)$ and lymph node metastasis $(P=0.054)$ (Table 5). Nuclear grade showed no association with age or laterality.

\section{MIB-1 Labeling Index and Their Association with Nuclear Grade and Prognosis}

To confirm our finding of nuclear grade on H\&Estained slides, we then compared our results to MIB-1 labeling index, a known marker of proliferation. When comparing MIB-1 labeling index and mitotic count as continuous variables, a moderately significant positive correlation was found (rank correlation coefficient $=0.44, P<0.001$ ). Tumors with high mitotic count $(n=59)$ had the highest MIB-1 labeling index (mean \pm s.d., 22.0 \pm 15.8 ), followed by intermediate $(n=53,12.5 \pm 11.4)$ and low $(n=46,9.0 \pm 7.8) \quad(P<0.001)$. Tumors with severe nuclear atypia $(n=34)$ had the highest MIB-1 labeling index (mean \pm s.d., 21.6 \pm 17.8 ), followed by moderate $(n=50,14.5 \pm 12.8)$ and mild $(n=74,12.3 \pm 10.7)(P=0.037)$.

Furthermore, patients with high MIB-1 labeling index $(n=88)$ had significantly worse median overall survival (12 months) than low MIB-1 labeling index $(n=70,23$ months $)(P<0.001$; Figure 5a). Among patients who underwent complete resection, patients with high MIB-1 labeling index $(n=68)$ had shorter median time to recurrence (16 months) than low MIB-1 labeling index $(n=55,25$ months $)$ $(P=0.048$; Figure 5b).

\section{Discussion}

Among the three main histologic types of diffuse malignant pleural mesothelioma in the 2004 WHO Classification-epithelioid, biphasic, and 

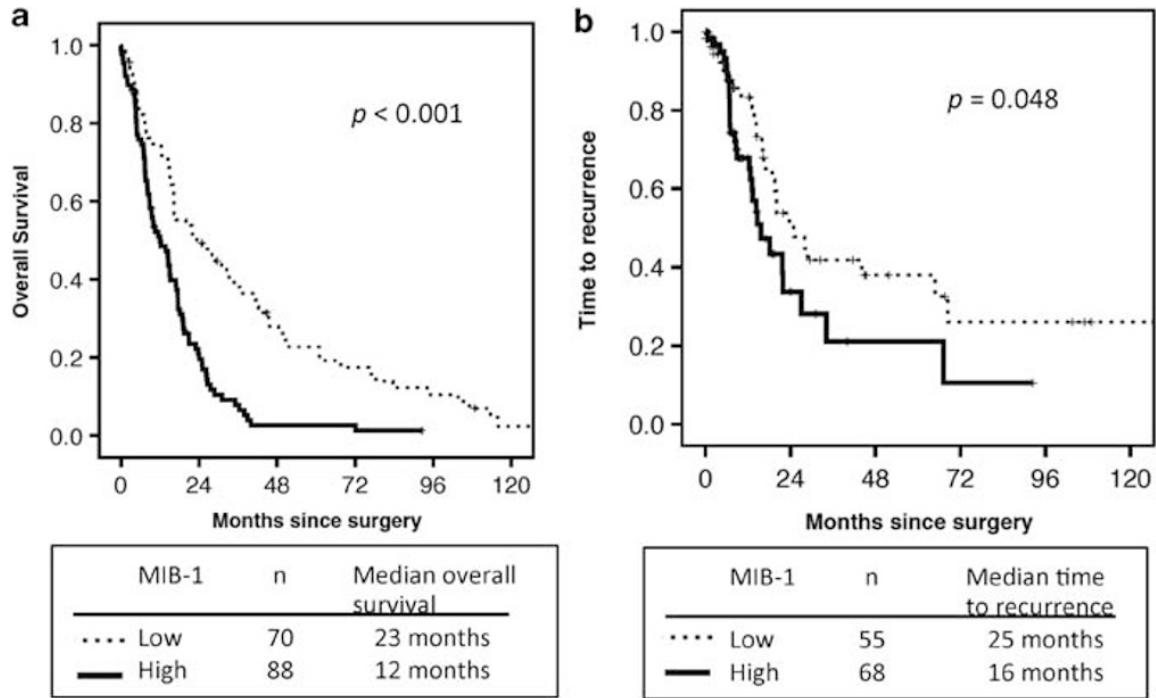

Figure 5 Overall survival and time to recurrence by MIB-1 labeling index. (a) Patients with high MIB-1 labeling index had significantly worse median overall survival than low MIB-1 labeling index. (b) Among patients who underwent complete resection, patients with high MIB-1 labeling index had shorter median time to recurrence than low.

sarcomatoid, ${ }^{20}$ epithelioid subtype is the most prevalent and has the best prognosis. ${ }^{4-9}$ Currently, there is a lack of prognostic factors to further stratify clinical outcomes in epithelioid diffuse malignant pleural mesothelioma patients. The available clinical parameters in our series (T1-2 vs T3-4, No vs $\mathrm{N} 1-3$, and stages I-II vs III-IV) at the best can differentiate patients by overall survival between 15 and 20 months, with a distribution of $\sim 60 \mathrm{vs} 40 \%$. The available pathological features (lymphatic and vascular invasion) at the best can differentiate outcome by overall survival of 10 vs 20 months, with a distribution of $\sim 70$ vs $30 \%$. In an effort to further stratify clinical outcome and investigate the biology of epithelioid diffuse malignant pleural mesothelioma, we have recently proposed a morphological classification. ${ }^{29}$ In this study, we propose and demonstrate the prognostic utility of a nuclear grading system in epithelioid diffuse malignant pleural mesothelioma.

Based on an investigation of a large series of epithelioid diffuse malignant pleural mesothelioma, the nuclear grading system we propose is (1) costeffective in that the assessment can be performed on routine H\&E slides, (2) practical to implement as most pathologists are very familiar with nuclear atypia and mitotic counts that are commonly utilized in other cancers, (3) stratifies epithelioid diffuse malignant pleural mesothelioma patients into three distinct groups with relatively larger median overall survival differences (28 vs 14 vs 5 months) compared with the available clinicopathological factors discussed above, and (4) stratifies patients into groups with distinct distribution (46 vs 39 vs 15\%). The strength of our proposed nuclear grading is demonstrated by the fact that it remained significant in subcohorts of stages I-II and stage III patients and also in its ability to predict time to recurrence. Furthermore, these findings remained significant after excluding patients with a pleomorphic subtype, which we recently reported as the subtype showing the poorest prognosis among epithelioid diffuse malignant pleural mesothelioma. ${ }^{29}$

In addition to prognostic stratification, nuclear grade also showed associations with tumor biology such as lymphatic invasion, vascular invasion, higher TNM stage, and an increased tendency for higher $\mathrm{T}$ stage and lymph node metastasis. These findings are consistent with what has been observed in other malignancies ${ }^{15,17,26,31,32}$ and confirms that our grading system correlates with the malignant potential of epithelioid diffuse malignant pleural mesothelioma.

We evaluated seven nuclear features in the current study, out of which two-nuclear atypia and mitotic count-were independent prognostic factors. Nuclear atypia has been reported as a prognostic factor in various tumors such as lung, ${ }^{23,32}$ breast, ${ }^{11}$ renal cell, ${ }^{12,13}$ and bladder carcinomas. ${ }^{14,15}$ Similar to what is observed in other cancers, ${ }^{33}$ nuclei of individual diffuse malignant pleural mesothelioma tumor cells vary in size, shape, and chromatin pattern, both in comparison with normal nuclei and also among the tumor cells. In our study, nuclear atypia, chromatin pattern, and prominence of nucleoli were closely related to each other, and each factor was associated with worse overall survival. Multivariate analysis of nuclear features revealed nuclear atypia as an independent prognostic factor.

In our series, mitotic count was one of the most important prognostic variables. This result is consistent with other studies in non-small cell lung 
carcinoma, ${ }^{34,35}$ breast carcinoma, ${ }^{10,11,21}$ bladder carcinoma, ${ }^{15}$ and sarcoma. ${ }^{36-38}$ In mesothelioma, mitotic count in peritoneal mesothelioma ${ }^{27}$ and MIB-1 labeling index in pleural mesothelioma ${ }^{39,40}$ have been previously reported as prognostic factors. To the best of our knowledge, however, this is the first report to show the prognostic significance of mitotic count in a large series of epithelioid diffuse malignant pleural mesothelioma. Our findings on H\&E-stained slides were confirmed by comparing with MIB-1 labeling index. MIB-1 labeling index correlated with mitotic count and nuclear atypia, and stratified overall survival and time to recurrence in our cohort. An important advantage of mitotic count over MIB-1 is that it can be determined using H\&E slides within routine clinical work.

Atypical mitoses have been well recognized as one of the histologic factors to determine malignant potential in adrenocortical tumors and pheochromocytomas of the adrenal gland. ${ }^{28,41}$ In peritoneal mesothelioma, Cerruto et $a^{27}$ reported that the presence of atypical mitoses was a significant indicator of poor survival. In this study, we observed similar results for diffuse malignant pleural mesothelioma patients with atypical mitoses but observed mitotic count as being a stronger prognostic factor.

One important issue in reporting histopathological results is the issue of interobserver variability, which has been addressed in nuclear grading, ${ }^{10,42}$ mitoses, ${ }^{43,44}$ and atypical mitoses. ${ }^{45}$ Concerns of interobserver variability and reproducibility of nuclear grading have been answered in earlier publications by utilizing well-defined criteria, ${ }^{24,28}$ which were used in our study.

In recent years, several attempts have been made to develop a better classification for epithelioid diffuse malignant pleural mesothelioma. ${ }^{5,9,46-49}$ Our comprehensive evaluation of a histologic nuclear grading system suggests that nuclear features are important prognostic markers in epithelioid diffuse malignant pleural mesothelioma and can be incorporated into future studies investigating clinical, molecular, and radiographic findings. This nuclear grading system provides simple and useful prognostic information for individual patients and will help physicians in deciding clinical management. Most pathologists are familiar with grading systems based on nuclear features as similar methods are applied to tumors in other organs. ${ }^{10,11}$ As such, our findings in nuclear grading of epithelioid diffuse malignant pleural mesothelioma by nuclear atypia and mitosis should be readily applicable in clinical diagnosis and research.

\section{Acknowledgements}

We thank Joe Dycoco for his help with the Mesothelioma database within the Division of Thoracic Service, Department of Surgery, Avani Giri and Louie Lopez (Pathology Core Facility) for their help in making tissue microarray, and Irina Linkov (Pathology Core Facility) for her technical assistance in immunohistochemistry. This work was supported in part by Mesothelioma Applied Research Foundation (MARF) Grant in memory of Lance S Ruble, William $\mathrm{H}$ Goodwin and Alice Goodwin, the Commonwealth Foundation for Cancer Research and the Experimental Therapeutics Center, Stony Wold-Herbert Fund, New York State Empire Clinical Research Investigator Program (ECRIP), AATS-Third Edward D Churchill Research Scholarship, IASLC-International Association for the Study of Lung Cancer Young Investigator Award, National Lung Cancer Partnership/LUNGevity Foundation Research Grant, U54CA137788/ U54CA132378 from the National Cancer Institute, and PR101053 from the Department of Defense.

\section{Disclosure/conflict of interest}

The authors declare no conflict of interest.

\section{References}

1 Churg A, Cagle PT, Roggli VL. Tumors of the Serosal Membranes, Series IV edn Vol., American Registry of Pathology: Washington DC, 2006;33-72 pp.

2 Robinson BWS, Lake RA. Advances in malignant mesothelioma. N Engl J Med 2005;353:1591-1603.

3 Sugarbaker DJ, Flores RM, Jaklitsch MT, et al. Resection margins, extrapleural nodal status, and cell type determine postoperative long-term survival in trimodality therapy of malignant pleural mesothelioma: results of 183 patients. J Thorac Cardiovasc Surg 1999;117:54-65.

4 Rusch VW, Venkatraman ES. Important prognostic factors in patients with malignant pleural mesothelioma, managed surgically. Ann Thorac Surg 1999; 68:1799-1804.

5 Flores RM, Zakowski M, Venkatraman E, et al. Prognostic factors in the treatment of malignant pleural mesothelioma at a large tertiary referral center. J Thorac Oncol 2007;2:957-965.

6 Arrossi AV, Lin E, Rice D, Moran CA. Histologic assessment and prognostic factors of malignant pleural mesothelioma treated with extrapleural pneumonectomy. Am J Clin Pathol 2008;130:754-764.

7 Curran D, Sahmoud T, Therasse P, et al. Prognostic factors in patients with pleural mesothelioma: the European Organization for Research and Treatment of Cancer experience. J Clin Oncol 1998;16:145-152.

8 Borasio P, Berruti A, Bille A, et al. Malignant pleural mesothelioma: clinicopathologic and survival characteristics in a consecutive series of 394 patients. Eur J Cardiothorac Surg 2008;33:307-313.

9 Ak G, Metintas S, Metintas M, et al. Prognostic factors according to the treatment schedule in malignant pleural mesothelioma. J Thorac Oncol 2009;4: 1425-1430.

10 Meyer JS, Alvarez C, Milikowski C, et al. Breast carcinoma malignancy grading by Bloom-Richardson system vs proliferation index: reproducibility of grade 
and advantages of proliferation index. Mod Pathol 2005;18:1067-1078.

11 Thomas JS, Kerr GR, Jack WJ, et al. Histological grading of invasive breast carcinoma-a simplification of existing methods in a large conservation series with long-term follow-up. Histopathology 2009;55:724-731.

12 Delahunt B. Advances and controversies in grading and staging of renal cell carcinoma. Mod Pathol 2009;22(Suppl 2):S24-S36.

13 Rioux-Leclercq N, Karakiewicz PI, Trinh QD, et al. Prognostic ability of simplified nuclear grading of renal cell carcinoma. Cancer 2007;109:868-874.

14 Epstein JI. The new World Health Organization/ International Society of Urological Pathology classification for TA, T1 bladder tumors: is it an improvement? Crit Rev Oncol Hematol 2003;47:83-89.

15 Lipponen PK, Eskelinen MJ, Jauhiainen $\mathrm{K}$, et al. Independent clinical, histological and quantitative prognostic factors in transitional-cell bladder tumours, with special reference to mitotic frequency. Int J Cancer 1992;51:396-403.

16 Cina SJ, Lancaster-Weiss KJ, Lecksell K, Epstein JI. Correlation of Ki-67 and p53 with the new World Health Organization/International Society of Urological Pathology Classification System for Urothelial Neoplasia. Arch Pathol Lab Med 2001;125:646-651.

17 Yang Q, Mori I, Sakurai T, et al. Correlation between nuclear grade and biological prognostic variables in invasive breast cancer. Breast Cancer 2001;8:105-110.

18 Greene F, Page D, Fleming I, et al. AJCC Cancer Staging Manual, 6th edn, Vol. Springer: New York, 2002; 207-208 pp.

19 Craighead JE, Abraham JL, Churg A, et al. The pathology of asbestos-associated diseases of the lungs and pleural cavities: diagnostic criteria and proposed grading schema. Report of the pneumoconiosis committee of the college of American pathologists and the national institute for occupational safety and health. Arch Pathol Lab Med 1982;106:544-596.

20 Travis W, Brambilla E, Muller-Hermelink H, Harris C. World Health Organization Classification of Tumours. Pathology and Genetics. Tumours of the Lung, Pleura, Thymus, and Heart. IARC Press: Lyon, France, 2004;125-144 pp.

21 van Diest PJ, van der Wall E, Baak JP. Prognostic value of proliferation in invasive breast cancer: a review. J Clin Pathol 2004;57:675-681.

22 Travis WD, Rush W, Flieder DB, et al. Survival analysis of 200 pulmonary neuroendocrine tumors with clarification of criteria for atypical carcinoid and its separation from typical carcinoid. Am J Surg Pathol 1998;22:934-944.

23 Barletta JA, Yeap BY, Chirieac LR. Prognostic significance of grading in lung adenocarcinoma. Cancer 2010;116:659-669.

24 Baak JP. Mitosis counting in tumors. Hum Pathol 1990;21:683-685.

25 Okudela K, Woo T, Mitsui $\mathrm{H}$, et al. Morphometric profiling of lung cancers. Its association with clinicopathologic, biologic, and molecular genetic features. Am J Surg Pathol 2010;34:243-255.

26 Maezawa N, Tsuta K, Shibuki Y, et al. Cytopathologic factors can predict invasion in small-sized peripheral lung adenocarcinoma with a bronchioloalveolar carcinoma component. Cancer 2006;108:488-493.

27 Cerruto CA, Brun EA, Chang D, et al. Prognostic significance of histomorphologic parameters in diffuse malignant peritoneal mesothelioma. Arch Pathol Lab Med 2006;130:1654-1661.

28 Thompson LD. Pheochromocytoma of the Adrenal gland Scaled Score (PASS) to separate benign from malignant neoplasms: a clinicopathologic and immunophenotypic study of 100 cases. Am J Surg Pathol 2002;26:551-566.

29 Kadota K, Suzuki K, Sima CS, et al. Pleomorphic epithelioid diffuse malignant pleural mesothelioma: a clinicopathological review and conceptual proposal to reclassify as biphasic or sarcomatoid mesothelioma. J Thorac Oncol 2011;6:896-904.

30 Heller G, Venkatraman E. A nonparametric test to compare survival distributions with covariate adjustment. JRSS-B 2004;66:719-733 .

31 Genega EM, Kapali M, Torres-Quinones $\mathrm{M}$, et al. Impact of the 1998 World Health Organization/ International Society of Urological Pathology classification system for urothelial neoplasms of the kidney. Mod Pathol 2005;18:11-18.

32 Nakazato Y, Minami Y, Kobayashi H, et al. Nuclear grading of primary pulmonary adenocarcinomas: correlation between nuclear size and prognosis. Cancer 2010;116:2011-2019.

33 Bignold LP. Pathogenetic mechanisms of nuclear pleomorphism of tumour cells based on the mutator phenotype theory of carcinogenesis. Histol Histopathol 2003;18:657-664.

34 Kobayashi Y, Yokose T, Kawamura K, et al. Cytologic factors associated with prognosis in patients with peripheral adenocarcinoma of the lung measuring $3 \mathrm{~cm}$ or less in greatest dimension. Cancer 2005; 105:44-51.

35 Poleri C, Morero JL, Nieva B, et al. Risk of recurrence in patients with surgically resected stage I non-small cell lung carcinoma: histopathologic and immunohistochemical analysis. Chest 2003;123:1858-1867.

36 Guillou L, Coindre JM, Bonichon F, et al. Comparative study of the National Cancer Institute and French Federation of Cancer Centers Sarcoma Group grading systems in a population of 410 adult patients with soft tissue sarcoma. J Clin Oncol 1997;15:350-362.

37 Hasegawa T, Yokoyama R, Matsuno Y, et al. Prognostic significance of histologic grade and nuclear expression of beta-catenin in synovial sarcoma. Hum Pathol 2001;32:257-263.

38 Rudolph P, Gloeckner K, Parwaresch R, et al. Immunophenotype, proliferation, DNA ploidy, and biological behavior of gastrointestinal stromal tumors: a multivariate clinicopathologic study. Hum Pathol 1998;29:791-800.

39 Beer TW, Buchanan R, Matthews AW, et al. Prognosis in malignant mesothelioma related to MIB 1 proliferation index and histological subtype. Hum Pathol 1998;29:246-251.

40 Comin CE, Anichini C, Boddi V, et al. MIB-1 proliferation index correlates with survival in pleural malignant mesothelioma. Histopathology 2000;36:26-31.

41 Stojadinovic A, Brennan MF, Hoos A, et al. Adrenocortical adenoma and carcinoma: histopathological and molecular comparative analysis. Mod Pathol 2003;16:742-751.

42 Dalton LW, Pinder SE, Elston CE, et al. Histologic grading of breast cancer: linkage of patient outcome with level of pathologist agreement. Mod Pathol 2000;13:730-735. 
43 Cross SS. Grading and scoring in histopathology. Histopathology 1998;33:99-106.

44 Silverberg SG. Reproducibility of the mitosis count in the histologic diagnosis of smooth muscle tumors of the uterus. Hum Pathol 1976;7:451-454.

45 Barry M, Sinha SK, Leader MB, Kay EW. Poor agreement in recognition of abnormal mitoses: requirement for standardized and robust definitions. Histopathology 2001;38:68-72.

46 Lopez-Rios F, Chuai S, Flores R, et al. Global gene expression profiling of pleural mesotheliomas: overexpression of aurora kinases and P16/CDKN2A deletion as prognostic Factors and critical evaluation of microarray-based prognostic prediction. Cancer Res 2006;66:2970-2979.

47 Wheatley-Price $\mathrm{P}$, Yang $\mathrm{B}$, Patsios $\mathrm{D}$, et al. Soluble mesothelin-related peptide and osteopontin as markers of response in malignant mesothelioma. J Clin Oncol 2010;28:3316-3322.

48 Ramos-Nino ME, Testa JR, Altomare DA, et al. Cellular and molecular parameters of mesothelioma. J Cell Biochem 2006;98:723-734.

49 Pass HI, Goparaju C, Ivanov S, et al. hsa-miR$29 \mathrm{C}^{*}$ is linked to the prognosis of malignant pleural mesothelioma. Cancer Res 2010;70: 1916-1924. 